\title{
Article \\ Cerebrospinal Fluid Parameters in Antisense Oligonucleotide-Treated Adult 5q-Spinal Muscular Atrophy Patients
}

\author{
Lars Hendrik Müschen ${ }^{1, *,+}$, Alma Osmanovic ${ }^{1,+}{ }^{+}$, , Camilla Binz ${ }^{1}$, Konstantin F. Jendretzky ${ }^{1}$, Gresa Ranxha ${ }^{1}$, \\ Paul Bronzlik ${ }^{2}$, Omar Abu-Fares ${ }^{2}$, Flavia Wiehler ${ }^{1}$, Nora Möhn ${ }^{1}{ }^{1}$, Martin W. Hümmert ${ }^{1}$, Stefan Gingele ${ }^{1}$, \\ Friedrich Götz ${ }^{2}$, Martin Stangel ${ }^{1}\left(\mathbb{D}\right.$, Thomas Skripuletz ${ }^{1}\left(\mathbb{D}\right.$, Olivia Schreiber-Katz ${ }^{1, \neq}$ and Susanne Petri $^{1, \ddagger}$
}

\section{check for} updates

Citation: Müschen, L.H.; Osmanovic A.; Binz, C.; Jendretzky, K.F.; Ranxha,

G.; Bronzlik, P.; Abu-Fares, O.;

Wiehler, F.; Möhn, N.; Hümmert,

M.W.; et al. Cerebrospinal Fluid

Parameters in Antisense

Oligonucleotide-Treated Adult

5q-Spinal Muscular Atrophy Patients.

Brain Sci. 2021, 11, 296. https://doi. org /10.3390/brainsci11030296

Academic Editor: Boel De Paepe

Received: 11 February 2021

Accepted: 24 February 2021

Published: 26 February 2021

Publisher's Note: MDPI stays neutral with regard to jurisdictional claims in published maps and institutional affiliations.

Copyright: (c) 2021 by the authors Licensee MDPI, Basel, Switzerland. This article is an open access article distributed under the terms and conditions of the Creative Commons Attribution (CC BY) license (https:// creativecommons.org/licenses/by/ $4.0 /)$.
1 Department of Neurology, Hannover Medical School, 30625 Hannover, Germany; osmanovic.alma@mh-hannover.de (A.O.); Binz.Camilla@mh-hannover.de (C.B.); Konstantin.Jendretzky@stud.mh-hannover.de (K.F.J.); Ranxha.gresa@mh-hannover.de (G.R.); Wiehler.Flavia@mh-hannover.de (F.W.); moehn.nora@mh-hannover.de (N.M.); huemmert.martin@mh-hannover.de (M.W.H.); gingele.stefan@mh-hannover.de (S.G.); stangel.martin@mh-hannover.de (M.S.); skripuletz.thomas@mh-hannover.de (T.S.);

Schreiber-Katz.Olivia@mh-hannover.de (O.S.-K.); petri.susanne@mh-hannover.de (S.P.)

2 Department of Diagnostic and Interventional Neuroradiology, Hannover Medical School, 30625 Hannover, Germany; Bronzlik.paul@mh-hannover.de (P.B.);

Abu-Fares.omar@mh-hannover.de (O.A.-F.); Goetz.friedrich@mh-hannover.de (F.G.)

* Correspondence: Mueschen.Lars@mh-hannover.de; Tel.: +49-511-532-2392; Fax: +49-511-532

+ Contributed equally as first authors to the manuscript.

$\ddagger$ Contributed equally as senior authors to the manuscript.

Abstract: Approval of nusinersen, an intrathecally administered antisense oligonucleotide, for the treatment of 5q-spinal muscular atrophy (SMA) marked the beginning of a new therapeutic era in neurological diseases. Changes in routine cerebrospinal fluid (CSF) parameters under nusinersen have only recently been described in adult SMA patients. We aimed to explore these findings in a real-world setting and to identify clinical and procedure-associated features that might impact CSF parameters. Routinely collected CSF parameters (leukocyte count, lactate, total protein, CSF/serum albumin quotient (QAlbumin), oligoclonal bands) of 28 adult SMA patients were examined for up to 22 months of nusinersen treatment. Total protein and QAlbumin values significantly increased in the first 10 months, independent of the administration procedure. By month 14, no further increases were detected. Two patients developed transient pleocytosis. In two cases, positive oligoclonal bands were found in the beginning and in four patients throughout the whole observation period. No clinical signs of inflammatory central nervous system disease were apparent. Our data confirm elevated CSF total protein and QAlbumin during nusinersen treatment. These alterations may be caused by both repeated lumbar punctures and the interval between procedures rather than by the medication itself. Generally, there were no severe alterations of CSF routine parameters. These results further underline the safety of nusinersen therapy.

Keywords: spinal muscular atrophy (SMA); nusinersen; antisense oligonucleotide (ASO); cerebrospinal fluid (CSF); lumbar puncture

\section{Introduction}

With U.S. Food and Drug Administration (FDA) approval of the antisense oligonucleotide (ASO) nusinersen, the first disease-modifying treatment for 5q-spinal muscular atrophy (SMA) has become available [1]. SMA is an inherited neuromuscular disorder leading to a broad spectrum of clinical phenotypes (SMA types 0/1-4) with slowly progressive muscle weakness and atrophy [2,3]. The majority of patients carry a homozygous deletion of exon 7 and/or 8 of the survival motor neuron (SMN)1 gene, resulting in degeneration of 
anterior horn cells in the spinal cord and motor nuclei of the lower brainstem. The almost identical SMN2 gene, which is commonly present in several copies, differs only in a single nucleotide. This change causes the disruption of an exonic splice enhancer in exon 7 , and therefore, the gene encodes only low levels of the functional SMN protein [4]. ASOs are small single-stranded nucleic acid polymers that can modulate the gene expression via various mechanisms [5]. ASO-based therapies in SMA modify splicing of SMN2 at the pre-mRNA level and thereby increase the production of the functional, full-length SMN protein [6]. Nusinersen has been shown to effectively target the central nervous system and substantially prolong survival and improve motor function in SMA patients $[7,8]$. A major disadvantage of ASOs is their inability to penetrate the blood-brain barrier [5]. Hence, nusinersen must be repeatedly administered intrathecally by lumbar puncture (LP) on days $0,14,28$, and 63 (loading period), followed by injections every four months (maintenance period). Phase 1 and 2 clinical trials have revealed no safety concerns regarding cerebrospinal fluid (CSF) routine parameters such as total cell count, protein, glucose, inflammatory cytokines, and anti-nusinersen antibodies [7,9]. In a cohort of 25 adolescent and adult SMA type 2 and 3 patients, a slight increase in total CSF protein and CSF/serum albumin quotient (QAlbumin) was detected after the loading period on day 63 compared to baseline [10]. In a larger cohort of 63 SMA patients, this observation was confirmed over a longer treatment period [11]. Besides CSF protein alterations, routine CSF analysis revealed the presence of inclusions in macrophages during nusinersen treatment [12]. A potential impact of repeated LP on CSF protein elevation was suggested by Wurster and colleagues [11]. A slowdown of CSF flow throughout the therapy was hypothesized, though no clinical signs of hydrocephalus were found. However, data on changes in CSF routine parameters in ASO-treated patients against the background of repeated LPs are still limited. It has not been elucidated so far whether the above-mentioned findings are reproducible in an independent adult SMA cohort and whether CSF routine parameter alterations are associated with the treatment or with repeated LP. The objective of our study therefore was to gain further knowledge of the potential impact of nusinersen or its administration on CSF routine parameters and the tolerability of nusinersen according to CSF parameters in SMA patients in a real-world setting. We present the following study in accordance with the Strengthening the Reporting of Observational Studies in Epidemiology (STROBE) reporting checklist [13].

\section{Materials and Methods}

\subsection{Standard Protocol Approvals, Registrations, and Patient Consents}

This study was approved by the local ethics committee of the Hannover Medical School (approval number 2413-2014). All participants gave written informed consent to participate in the study and publication of pseudonymous cohort data before study enrollment.

\subsection{Participants and Sampling}

In this prospective, single-center, observational study, CSF and serum samples of patients with confirmed 5q-associated SMA treated with nusinersen at the Department of Neurology at the Hannover Medical School were collected between November 2017 and December 2019. Clinical parameters and demographics such as age, disease duration, history of scoliosis and spondylodesis, SMA type (2-4), and SMN2 copy number were collected at baseline. The route of nusinersen administration was either by conventional LP or computed tomography (CT)-guided LP. In this study, only CT-guided LP instead of fluoroscopy-guided LP was performed due to better tolerability and feasibility [14]. The motor function outcome was measured by physiotherapists at baseline and each treatment visit using the Revised Upper Limb Module (RULM) score [15] and the Hammersmith Functional Motor Scale Expanded (HFMSE) [16]. The RULM comprises 20 items rating the arm function, totaling 37 points. Higher scores indicate better function. Specifically designed and validated for SMA patients, the HFMSE contains 33 items and captures 
mainly gross motor function of major joints and body regions. The score for each item ranges from 0 to 2, with a maximum of 66 points. Additionally, the six-minute walk test (6MWT) was recorded in ambulatory patients at each treatment time point [17]. Side effects, including LP-related adverse events (i.e., cephalgia, neck pain, back pain, dizziness, and nausea), were evaluated at each treatment time point by a direct patient interview. CSF and serum samples were collected before nusinersen injections at the following day (d) or month (m) of treatment: $\mathrm{d} 0, \mathrm{~d} 14, \mathrm{~d} 28, \mathrm{~d} 63, \mathrm{~m} 6, \mathrm{~m} 10, \mathrm{~m} 14, \mathrm{~m} 18$, and $\mathrm{m} 22$. The following CSF and serum parameters were routinely determined: leukocyte count; erythrocytes; total protein; lactate; CSF/serum albumin quotient (QAlbumin); CSF/serum immunoglobulin G (IgG), immunoglobulin A (IgA), and immunoglobulin M (IgM) quotients; and oligoclonal bands (OCB).

\subsection{Sample Analysis}

All CSF and serum samples were collected before nusinersen administration and were further analyzed within one hour after LP. Determination of the CSF leukocyte count and protein analysis of CSF and corresponding serum samples were performed, as previously described [18]. Briefly, the CSF leukocyte count was manually determined with a FuchsRosenthal counting chamber. A CSF leukocyte count of $>5$ cells $/ \mu \mathrm{L}$ was considered pathologically increased. CSF cytology specimens of nusinersen-treated SMA patients have previously been published and were not part of this study [12]. A cell-free supernatant was used for protein analysis, and the protein concentration of the CSF was assessed by the Bradford dye-binding procedure (Beckmann Coulter DU730 Spectrophotometer, Brea, CA, USA). Albumin and immunoglobulins in the CSF and serum were determined by kinetic nephelometry (Beckman Coulter IMMAGE). For evaluation of the blood-CSF barrier function, the age-adjusted upper limit of QAlbumin was used according to the formula QAlbumin $=4+\left(\right.$ age in years $\left./ 15 \times 10^{-3}\right)$. Intrathecal immunoglobulin synthesis for IgG, $\operatorname{Ig} \mathrm{A}$, and IgM was measured regarding Reiber's revised hyperbolic function referring IgG, IgA, and IgM quotients to QAlbumin [19]. OCB were assessed by isoelectric focusing in polyacrylamide gels with consecutive silver staining [20]. OCB types 2 and 3-both indicating IgG synthesis-were summarized as positive findings. Since contamination by erythrocytes causes false results of CSF routine parameter analysis regarding the cell count, total protein, or QAlbumin, all samples with an erythrocyte count of $>2500 / \mu \mathrm{L}$ were excluded [18].

\subsection{Statistical Analysis}

All statistical analyses were performed using either IBM SPSS Statistics version 26 (SPSS Inc., Chicago, IL, USA) or GraphPad Prism 7.0 (GraphPad Software Inc., San Diego, CA, USA). According to the Shapiro-Wilk test, values for the CSF cell count, CSF total protein, QAlbumin, and OCB were not normally distributed. Therefore, the Wilcoxon signed-rank test was used for comparison of CSF values within the SMA patient group and at every treatment time point. Additionally, we stepwise excluded SMA patients with outlying CSF protein parameters $(n=1, S 16)$ and SMA patients with CSF-blood barrier dysfunction at baseline $(n=5$, S00, S04, S06, S10, S19) and compared CSF total protein and QAlbumin values by using the Wilcoxon signed-rank test. We used the Mann-Whitney Utest to examine the influence of CT-guided LP at every time point. We analyzed associations between CSF routine parameters and clinical parameters (age, RULM, HFMSE, 6MWT) by using Spearman's correlation coefficient (rho). For investigating the associations between SMA type, LP method, SMN2 copy number, side effects, and CSF routine parameters, the point-biserial correlation coefficient $(\mathrm{rPB})$ was used. To investigate the association between sex, LP technique, OCB status, and procedure-related side effects, the chi-square test was used. The phi-coefficient (phi) was used to describe the effect size. We applied a linear mixed model with restricted maximum likelihood analysis, with treatment time points $\mathrm{d} 0, \mathrm{~d} 14, \mathrm{~d} 63, \mathrm{~m} 6, \mathrm{~m} 10, \mathrm{~m} 14$, and $\mathrm{m} 18$ as repeated measurements. With either protein concentration or QAlbumin as a dependable variable, we controlled other factors such as 
age, gender, or LP method, which may be confounding in univariate analysis. Additionally, estimated marginal means were calculated for the treatment time point, gender, and LP method. For post hoc multiple comparisons, $p$-values were corrected by Bonferroni's procedure. For all statistical tests, a two-tailed significance level of $p<0.05$ was considered statistically significant. Because of the explorative character of this study, all statistical test results were interpreted as hypothesis generating and not as confirmatory. No adjustment for multiple testing was done. Missing data of CSF routine parameters or incomplete analysis of any participant's CSF were not taken into account for this calculation.

\section{Results}

\subsection{Participants' Characteristics}

Demographic data of participants are summarized in Table 1. Twenty-eight adult SMA patients (SMA type 2, $n=10$; SMA type 3, $n=17$; SMA type $4, n=1$ ) with a median age of 36 years (range 19-65 years) were enrolled in this study. The one SMA type 4 patient was further analyzed together with SMA type 3 patients. The majority of patients were male $(64.3 \%)$. Almost every second patient $(46.4 \%)$ underwent CT-guided LP. The reason for CT-guided LP in the majority of cases was scoliosis (84.6\%). In two patients, CT-guided LP was performed after conventional LP had failed beforehand. In seven SMA patients who underwent CT-guided LP for nusinersen treatment, transforaminal injections were necessary at least once during the treatment course. The median scores for the HFMSE and RULM at d0 were 9.5 (range 0-63) and 18.5 (range 0-37), respectively. Ambulatory patients reached 390 meters in the 6MWT in the median (range 0-512 m). It took on average 32.5 years (range 2-62.5 years) from symptom onset to initiation of nusinersen therapy. Two patients discontinued the therapy after 6 and 14 months, respectively. No side effects were reported in $58 \%$ of all conducted LP $(n=179)$. Reports on side effects were missing for three LPs. Reported side effects were mainly $(80.2 \%)$ classified as procedure related.

Table 1. Demographic characteristics of SMA patient groups. Age, disease duration until therapy start, HFMSE, 6MWT, and RULM are described as median with range. Above-listed values for the HFMSE, 6MWT, and RULM were collected at baseline (d0). The SMN2 copy number was not available in one 58-year-old SMA type 3 male patient. 6MWT: 6-minute walk test; CNS: central nervous system; CT: computed tomography; HFMSE: Hammersmith Functional Motor Scale Expanded; LP: lumbar puncture; OCB: oligoclonal bands; RULM: Revised Upper Limb Module; SMA: spinal muscular atrophy; SMN2 gene: survival motor neuron 2 gene.

\begin{tabular}{|c|c|c|c|}
\hline & SMA (Total) & SMA 2 & SMA $3 / 4$ \\
\hline$n$ & 28 & 10 & 18 \\
\hline Women & $10(35.7 \%)$ & $4(40 \%)$ & $6(33.3 \%)$ \\
\hline Age, years (range) & $36(19-65)$ & $34(20-51)$ & $39(19-65)$ \\
\hline SMN2 copy $\geq 3$ & $15(53.6 \%)$ & $1(10 \%)$ & $14(82.4 \%)$ \\
\hline Disease duration, years (range) & $32.5(2-61.5)$ & $33.25(19.42-50)$ & $31.75(2-61.5)$ \\
\hline HFMSE & $9.5(0-63)$ & $0.5(0-11)$ & $35(3-63)$ \\
\hline 6MWT (m) & $390(0-512)$ & 0 & $390(42-512)$ \\
\hline RULM & $18.5(0-37)$ & $9.5(0-21)$ & $29(12-37)$ \\
\hline CT-guided LP & $13(46.4 \%)$ & $10(100 \%)$ & $3(16.7 \%)$ \\
\hline Abnormal CSF leukocyte count at baseline (\%) & $0(0 \%)$ & $0(0 \%)$ & $0(0 \%)$ \\
\hline Abnormal CSF lactate at baseline (\%) & $0(0 \%)$ & $0(0 \%)$ & $0(0 \%)$ \\
\hline Abnormal CSF-blood barrier dysfunction at baseline (\%) & $6(21.4 \%)$ & $2(20 \%)$ & $4(22.2 \%)$ \\
\hline Positive OCB at baseline (\%) & $2(7.1 \%)$ & $2(20 \%)$ & $0(0 \%)$ \\
\hline
\end{tabular}




\subsection{CSF Routine Parameters}

CSF routine parameters of SMA patients were available for baseline (d0; $n=28), \mathrm{d} 14$ $(n=28), \mathrm{d} 28(n=26), \mathrm{d} 63(n=27), \mathrm{m} 6(n=24), \mathrm{m} 10(n=22), \mathrm{m} 14(n=15), \mathrm{m} 18(n=7)$, and m22 $(n=2)$. In total, 179 CSF samples of 28 patients were collected. Data were missing for leukocyte count ( $n=3$ samples), lactate $(n=33)$, total protein ( $n=33$ samples), and QAlbumin ( $n=34$ samples) due to various reasons (i.e., too little CSF volume, missing protein diagnostics, etc.). After blood correction by excluding all CSF samples with an erythrocyte count above 2500 cells $/ \mu \mathrm{L}, 161$ CSF leukocyte count values, 130 CSF lactate values, $136 \mathrm{CSF}$ total protein values, and 135 QAlbumin values were analyzed. Since data for $\mathrm{m} 22$ were only available for two patients, this time point was not included in the calculation. CSF/serum quotients of $\operatorname{IgG}, \operatorname{IgA}$, and $\operatorname{IgM}$ were not analyzed in this study, because intrathecal immunoglobulin synthesis was found only in one SMA patient. In Table 2, CSF routine parameters of SMA patients are displayed as the median and range, as well as the total number of analyzed samples. Figure 1 demonstrates CSF routine parameters as box plots.

Table 2. Overview of CSF routine parameters at the nusinersen application time points ( $\mathrm{d} 0$ to $\mathrm{m} 22$ ). Values for time point $\mathrm{m} 22$ were not further analyzed. Values are presented as the median and range. $n$ describes the number of analyzed samples. CSF: cerebrospinal fluid; d: day; m: month; QAlbumin: CSF/serum albumin quotient.

\begin{tabular}{|c|c|c|c|c|c|c|c|c|c|}
\hline Time Point & do & d14 & d28 & d63 & m6 & m10 & m14 & m18 & $\mathrm{m} 22$ \\
\hline $\begin{array}{l}\text { CSF leukocyte } \\
\text { count (cells } / \mu \mathrm{L})\end{array}$ & $\begin{array}{c}1.0 \\
(0.0-4.0) \\
n=26\end{array}$ & $\begin{array}{c}1.0 \\
(0.0-33.0) \\
n=25\end{array}$ & $\begin{array}{c}1.0 \\
(0.0-12.0) \\
n=23\end{array}$ & $\begin{array}{c}2.0 \\
(0.0-5.0) \\
n=25\end{array}$ & $\begin{array}{c}1.0 \\
(0.0-3.0) \\
n=23\end{array}$ & $\begin{array}{c}1.0 \\
(0.0-3.0) \\
n=18\end{array}$ & $\begin{array}{c}1.0 \\
(0.3-4.0) \\
n=13\end{array}$ & $\begin{array}{c}0.0 \\
(0.0-2.0) \\
n=7\end{array}$ & $\begin{array}{c}1.0 \\
(1.0-1.0) \\
n=2\end{array}$ \\
\hline $\begin{array}{l}\text { CSF lactate } \\
(\mathrm{mmol} / \mathrm{L})\end{array}$ & $\begin{array}{c}1.5 \\
(1.26-1.96) \\
n=22\end{array}$ & $\begin{array}{c}1.45 \\
(1.17-1.96) \\
n=18\end{array}$ & $\begin{array}{c}1.42 \\
(1.25-1.72) \\
n=16\end{array}$ & $\begin{array}{c}1.44 \\
(1.27-1.79) \\
n=20\end{array}$ & $\begin{array}{c}1.38 \\
(1.24-1.92) \\
n=19\end{array}$ & $\begin{array}{c}1.42 \\
(1.17-1.88) \\
n=16\end{array}$ & $\begin{array}{c}1.41 \\
(1.18-2.06) \\
n=11\end{array}$ & $\begin{array}{c}1.28 \\
(1.16-1.61) \\
n=7\end{array}$ & $\begin{array}{c}1.32 \\
(1.20-1.43) \\
n=2\end{array}$ \\
\hline $\begin{array}{l}\text { CSF total protein } \\
(\mathrm{mg} / \mathrm{L})\end{array}$ & $\begin{array}{c}353 \\
(211-588) \\
n=25\end{array}$ & $\begin{array}{c}367 \\
(211-587) \\
n=19\end{array}$ & $\begin{array}{c}371 \\
(210-583) \\
n=15\end{array}$ & $\begin{array}{c}414.5 \\
(198-817) \\
n=22\end{array}$ & $\begin{array}{c}447 \\
(258-748) \\
n=18\end{array}$ & $\begin{array}{c}409 \\
(187-624) \\
n=17\end{array}$ & $\begin{array}{c}375 \\
(173-907) \\
n=13\end{array}$ & $\begin{array}{c}415.5 \\
(239-606) \\
n=6\end{array}$ & $\begin{array}{c}266 \\
(214-318) \\
n=2\end{array}$ \\
\hline QAlbumin $\left(\times 10^{-3}\right)$ & $\begin{array}{c}4.85 \\
(1.6-9.04) \\
n=24\end{array}$ & $\begin{array}{c}4.82 \\
(2.73-10.57) \\
n=19\end{array}$ & $\begin{array}{c}4.79 \\
(1.94-9.46) \\
n=14\end{array}$ & $\begin{array}{c}5.77 \\
(2.88-11.92) \\
n=23\end{array}$ & $\begin{array}{c}5.79 \\
(3.4-13.67) \\
n=18\end{array}$ & $\begin{array}{c}5.01 \\
(1.83-11.23) \\
n=17\end{array}$ & $\begin{array}{c}4.41 \\
(1.76-16.26) \\
n=13\end{array}$ & $\begin{array}{c}5.33 \\
(1.98-8.94) \\
n=6\end{array}$ & $\begin{array}{c}2.54 \\
(1.88-3.2) \\
n=2\end{array}$ \\
\hline
\end{tabular}
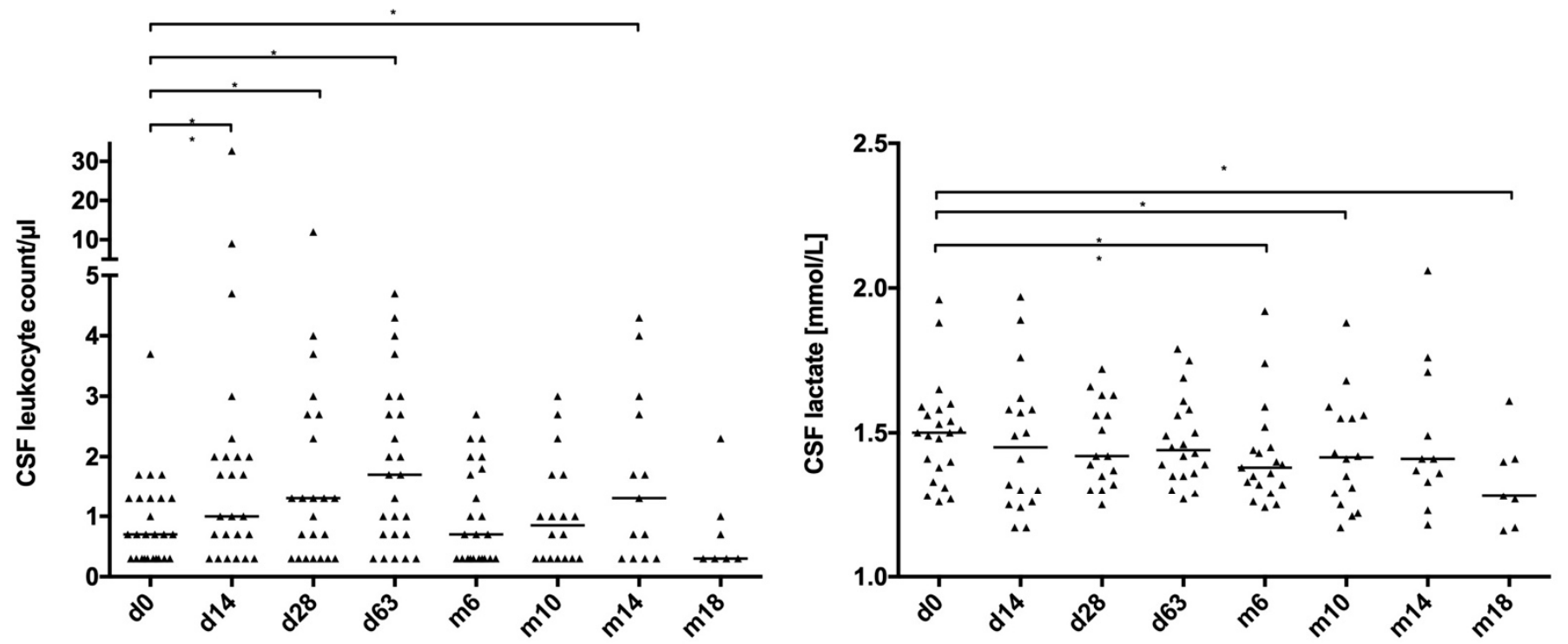

(a)

(b)

Figure 1. Cont. 


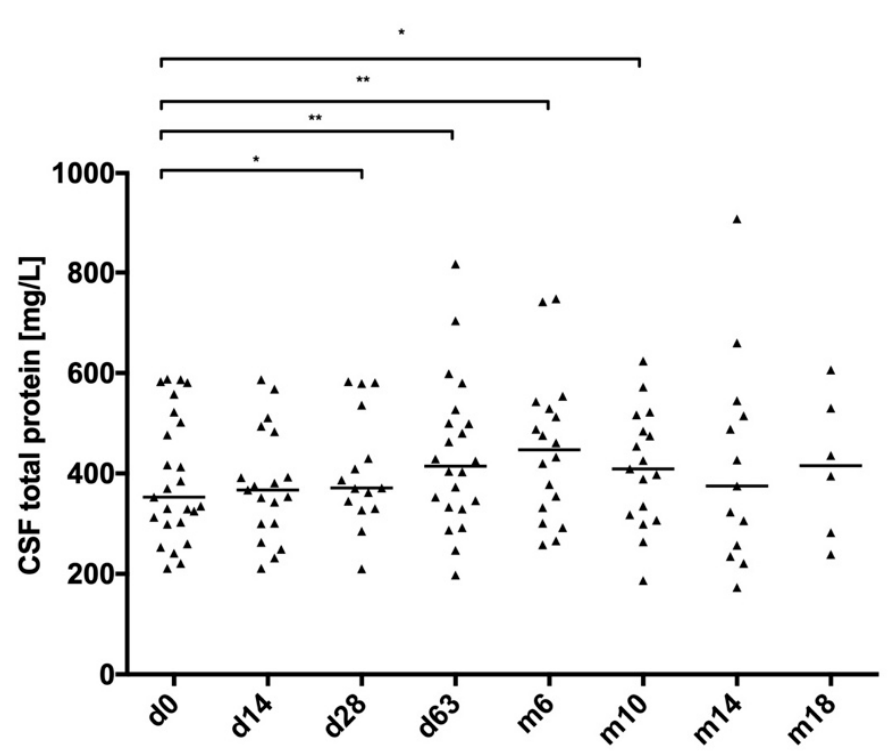

(c)

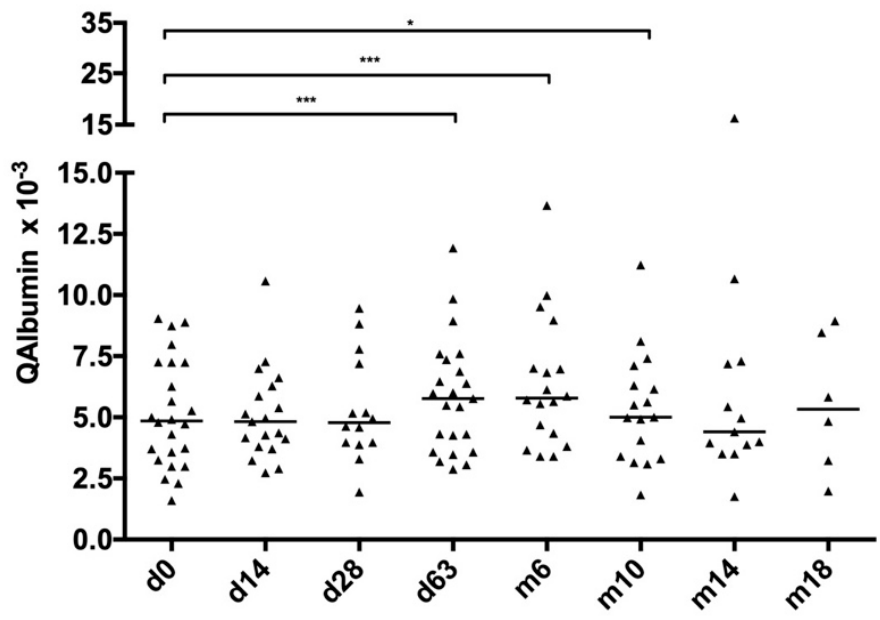

(d)

Figure 1. CSF routine parameters during nusinersen therapy (d0 to m18). (a) CSF leukocyte count and lactate, (b) CSF lactate, (c) CSF total protein, and (d) QAlbumin. Values displayed as scatter plots with the median. CSF: cerebrospinal fluid; d: day; m: month; QAlbumin: CSF/serum albumin quotient. *: $p \leq 0.05 ;{ }^{* *}: p \leq 0.01 ;{ }^{* * *}: p \leq 0.001$.

\subsubsection{CSF Leukocyte Count and Oligoclonal Bands}

Mild CSF pleocytosis $(9 / \mu \mathrm{L})$ was found in a 36-year-old SMA type 2 female patient (S11) at d14, i.e., two weeks after the first nusinersen administration. The LP was conducted conventionally. No intrathecal immunoglobulin synthesis according to the revised hyperbolic function by Reiber or CSF-specific OCB was found. Subsequently, the leukocyte count was $<5 / \mu \mathrm{L}$ during further treatment ( $\mathrm{d} 28$ to $\mathrm{m} 22$ ). In the CSF of a 32-year-old SMA type 3 male patient (S22), an elevated cell count was found at d14 $(33 / \mu \mathrm{L})$ and $\mathrm{d} 28(12 / \mu \mathrm{L})$. The LP was conducted via CT guidance by the standard interlaminar approach. At $\mathrm{d} 0$, the CSF leukocyte count was normal $(1 / \mu \mathrm{L})$. At m10, CSF pleocytosis was no longer detectable. However, intrathecal IgA synthesis was found at m10. At every time point (d0 to m10), weakly positive OCB were found in this patient.

In the second of the two patients with positive OCB at baseline, a 51-year-old SMA type 2 female patient (S02), OCB were also positive at both $\mathrm{d} 0$ and $\mathrm{d} 14$ to $\mathrm{m} 6$ as well as $\mathrm{m} 14$ to $\mathrm{m} 18$. Only at $\mathrm{m} 10$, no positive OCB were found. No intrathecal immunoglobulin synthesis (IgG, IgA, IgM) according to Reiber graphs and increased leukocyte count were present at any time point.

In two patients without CSF-specific OCB at baseline, a 45-year-old SMA type 3 male patient (S04) and a 39-year-old SMA type 3 female patient (S09), positive OCB were found at a single time point during further treatment (d14 and $\mathrm{m} 10$, respectively) but no longer in subsequent CSF samples.

In general, the leukocyte count in the CSF ranged from 1 to $5 / \mu \mathrm{L}$ in 24 of 26 patients. Despite mainly being within the normal range, an increase in the leukocyte count was observed between $\mathrm{d} 0$ and the following time points, with the exception of $\mathrm{m} 18$, reaching statistical significance between $\mathrm{d} 0$ and $\mathrm{d} 14(p=0.004), \mathrm{d} 0$ and $\mathrm{d} 28(p=0.024), \mathrm{d} 0$ and $\mathrm{d} 63$ $(p=0.015)$, and d 0 and $\mathrm{m} 14(p=0.038)$. Summarizing OCB results, in 2 of 24 tested SMA patients, positive OCB were found at baseline. Throughout therapy, four SMA patients tested positive for OCB. 


\subsubsection{CSF Total Protein, QAlbumin, and CSF Lactate}

At baseline, seven SMA patients (28\%) showed total protein values in the CSF above the upper reference level of $500 \mathrm{mg} / \mathrm{L}$ (range $502-588 \mathrm{mg} / \mathrm{L}$ ), and six (25\%) were found with a disturbed blood-CSF barrier function, five of those with an elevation of total protein. The patient with the highest total CSF protein levels in our study was a 57-year-old SMA type 3 male patient (S16). Total protein levels in this patient ranged from $583 \mathrm{mg} / \mathrm{L}$ (d0) to $907 \mathrm{mg} / \mathrm{L}$ (m14), rising from baseline to $817 \mathrm{mg} / \mathrm{L}$ at d63 and decreasing slightly to $742 \mathrm{mg} / \mathrm{L}$ at $\mathrm{m} 6$ and $624 \mathrm{mg} / \mathrm{L}$ at m10. From baseline on, QAlbumin values of this patient indicated CSF-blood barrier dysfunction at all time points (d0: $8.74 \times 10^{-3}$; d63: $\left.11.92 \times 10^{-3} ; \mathrm{m} 6: 13.67 \times 10^{-3} ; \mathrm{m} 10: 11.23 \times 10^{-3} ; \mathrm{m} 14: 16.26 \times 10^{-3}\right)$. Other CSF parameters (cell count, lactate, OCB) were within the normal range. The remaining 18 patients had CSF protein levels within the reference range $(211-477 \mathrm{mg} / \mathrm{L})$. While there was no significant difference in total protein after the first injection of nusinersen, from $\mathrm{d} 28$ onward, significant changes were found (d0 to d28: $353 \mathrm{mg} / \mathrm{L}$ vs. $371 \mathrm{mg} / \mathrm{L}, p=0.033$; d0 to d63: $353 \mathrm{mg} / \mathrm{L}$ vs. $414.5 \mathrm{mg} / \mathrm{L}, p=0.004$; d0 to $\mathrm{m} 6: 353 \mathrm{mg} / \mathrm{L}$ vs. $447 \mathrm{mg} / \mathrm{L}, p=0.003$; d0 to m10: $353 \mathrm{mg} / \mathrm{L}$ vs. $409 \mathrm{mg} / \mathrm{L}, p=0.044)$. After m14, the increase persisted but was no longer significant. Fifteen patients $(53.6 \%)$ were at least once above the upper reference level of $500 \mathrm{mg} / \mathrm{L}$ during therapy. After the first and second administration of nusinersen, no significant changes in QAlbumin were detected. We found significant changes in QAlbumin between $\mathrm{d} 0$ and $\mathrm{d} 63\left(4.85 \times 10^{-3}\right.$ vs. $\left.5.77 \times 10^{-3}, p=0.001\right)$, between $\mathrm{d} 0$ and $\mathrm{m} 6\left(4.85 \times 10^{-3}\right.$ vs. $\left.5.79 \times 10^{-3}, p=0.001\right)$, and between $\mathrm{d} 0$ and $\mathrm{m} 10\left(4.85 \times 10^{-3}\right.$ vs. $\left.5.01 \times 10^{-3}, p=0.041\right)$. Similar to changes in total protein, no further significant changes in QAlbumin were found from $\mathrm{m} 14$ onward. According to age-dependent adjustments for QAlbumin, 12 patients (42.9\%) displayed CSF-blood barrier dysfunction at least once throughout therapy. Because of the very high CSF total protein values and corresponding QAlbumin values, we repeated the statistical analysis after excluding the above-mentioned SMA type 3 patient (S16). We then still found a significant difference in total protein values between $\mathrm{d} 0$ and $\mathrm{d} 28$ (Table $\mathrm{S} 1, p=0.033$ ). QAlbumin values first differed significantly between $\mathrm{d} 0$ and $\mathrm{d} 63$ (Table $\mathrm{S} 1, p=0.001$ ). A significant difference in the total protein and QAlbumin values was found until $\mathrm{m} 6$ (Table S1, total protein: $p=0.005$; QAlbumin: $p=0.001$ ). After excluding all SMA patients with a baseline dysfunctional CSF-blood barrier according to age-adjusted QAlbumin values ( $n=5$, here S00, S04, S06, S10, S19), we still detected a significant difference in both total protein (Table S2, $p=0.008$ ) and QAlbumin (Table S2, $p=0.026$ ) between $\mathrm{d} 0$ and $\mathrm{d} 28$. This significant difference remained present until m10 (Table S2; total protein: $p=0.01$; QAlbumin: $p=0.025$ ) and became insignificant thereafter. All 22 available lactate values at baseline were within the normal range between 1.26 and $1.96 \mathrm{mmol} / \mathrm{L}$. During the treatment course, lactate levels were mainly stable but showed significant differences between $\mathrm{d} 0$ and $\mathrm{m} 6(p=0.024), \mathrm{d} 0$ and $\mathrm{m} 10(p=0.034)$, and $\mathrm{d} 0$ and $\mathrm{m} 18(p=0.028)$. Table 3 depicts the proportion of the CSF-blood barrier dysfunction according to age-adjusted reference levels for QAlbumin throughout nusinersen therapy. 
Table 3. SMA patients with or without CSF-blood barrier dysfunction according to age-adjusted reference levels for QAlbumin throughout therapy (d0 to m22). CSF: cerebrospinal fluid; d: day; m: month; SMA: spinal muscular atrophy.

\begin{tabular}{cccc}
\hline \multirow{2}{*}{ Time Point } & $n$ & \multicolumn{2}{c}{ CSF-Blood Barrier Dysfunction } \\
Yes & No \\
\hline $\mathrm{d} 0$ & 24 & $6(25 \%)$ & 18 \\
\hline $\mathrm{d} 14$ & 19 & $3(15.8 \%)$ & 16 \\
\hline $\mathrm{d} 28$ & 14 & $1(7.1 \%)$ & 13 \\
\hline $\mathrm{d} 63$ & 22 & $7(31.8 \%)$ & 15 \\
\hline $\mathrm{m} 6$ & 18 & $7(38.9 \%)$ & 11 \\
\hline $\mathrm{m} 10$ & 17 & $5(29.4 \%)$ & 12 \\
\hline $\mathrm{m} 14$ & 13 & $3(23.1 \%)$ & 10 \\
\hline $\mathrm{m} 18$ & 6 & $2(33.3 \%)$ & 4 \\
\hline $\mathrm{m} 22$ & 2 & 0 & 2 \\
\hline
\end{tabular}

\subsection{Comparison of CSF Routine Parameters under Conventional and CT-Guided} Lumbar Puncture

In 13 patients, CT-guided lumbar puncture was necessary due to scoliosis and previous spinal surgery. Lactate, CSF total protein, and QAlbumin values did not differ significantly in patients undergoing CT-guided LP compared to those undergoing conventional LP at baseline. At all following injections, there was no significant difference between the CSF leukocyte count, CSF total protein levels, and QAlbumin values in patients who underwent CT-guided lumbar puncture (interlaminar or transforaminal). Only lactate levels significantly differed between patients with conventional versus CT-guided LP at $\mathrm{m} 10$ (1.52 mmol/L vs. $1.28 \mathrm{mmol} / \mathrm{L}, p=0.016)$ and $\mathrm{m} 14(1.63 \mathrm{mmol} / \mathrm{L}$ vs. $1.3 \mathrm{mmol} / \mathrm{L}$, $p=0.009)$. Lactate levels ranged below the upper level of normal in both groups at both time points (conventional LP: m10: 1.22-1.88 mmol/L and m14: 1.37-2.06 mmol/L; CTguided LP: m10: 1.17-1.43 mmol/L and m14: 1.18-1.41 mmol/L).

\subsection{Association of CSF Protein Values and Clinical Parameters}

No significant correlations between QAlbumin values at baseline (d0) and HFMSE, RULM, and 6MWT results were found. CSF total protein levels at baseline (d0) did not correlate with the HFMSE, RULM, and 6MWT. There was a positive correlation between QAlbumin at baseline $(\mathrm{d} 0)$ and age (rho $=0.522, p=0.009)$ as well as between total protein levels and age (rho $=0.548, p=0.005)$. During the observation period ( $\mathrm{d} 0$ to $\mathrm{m} 18)$, there was no significant correlation between QAlbumin or total protein levels and the HFMSE, RULM, and 6MWT but a correlation of age with QAlbumin (rho $=0.326, p<0.001$ ) and total protein levels (rho $=0.326, p<0.001$ ). We found a significant association between QAlbumin values and total protein levels and SMA type (QAlbumin: $\mathrm{rPB}=0.307, p<0.001$; total protein: $\mathrm{rPB}=0.38, p<0.001$ ), $\operatorname{sex}(\mathrm{QAlbumin}: \mathrm{rPB}=0.258, p=0.003$; total protein: $\mathrm{rPB}=0.275, p=0.001$ ), SMN2 copy number (QAlbumin: $\mathrm{rPB}=0.183, p=0.037$; total protein: $\mathrm{rPB}=0.269, p=0.002$ ), and modality of LP (QAlbumin: $\mathrm{rPB}=-0.274, p=0.001$; total protein: rho $=-0.34, p<0.001)$. Significantly higher total protein levels and higher QAlbumin values were found in SMA type 3 patients, in male patients, in patients with SMN2 copy number $\geq 3$, and in patients who underwent conventional lumbar puncture. QAlbumin values and total protein levels significantly correlated with procedure-related side effects (QAlbumin: $\mathrm{rPB}=-0.181, p=0.046$; total protein: $\mathrm{rPB}=-0.211, p=0.019$ ). Patients with lower CSF total protein levels or QAlbumin values experienced more procedure-related side effects. Overall, procedure-related side effects did not correlate with age, OCB status, and LP technique. However, a weak but significant association between sex and side effects was found: women reported procedure-related side effects in 50\% of conducted LPs 
compared to $25.3 \%$ in men (chi-square $=9.321$, phi $=-0.254, p=0.002$ ). The linear mixed model analysis confirmed our former approach of correlating QAlbumin values with the LP method (Table 4; $p=0.022, \mathrm{~F}=5.461$ ) and age (Table $4 ; p=0.009, \mathrm{~F}=7.214$ ), where we observed an additive effect (Table $4 ; p=0.008, \mathrm{~F}=7.308$ ). All post hoc evaluations were abandoned due to the lack of sufficient data density to perform the estimated marginal means.

Table 4. Predictors of CSF total protein and QAlbumin values. A mixed linear model was used. Time point refers to nusinersen injection ( $\mathrm{d} 0, \mathrm{~d} 14, \mathrm{~d} 28, \mathrm{~d} 63, \mathrm{~m} 6, \mathrm{~m} 10, \mathrm{~m} 14, \mathrm{~m} 18)$. LP method refers to CT-guided or conventional LP. CSF: cerebrospinal fluid; LP: lumbar puncture; QAlbumin: CSF/serum albumin quotient.

\begin{tabular}{|c|c|c|c|c|c|c|c|c|}
\hline & \multicolumn{4}{|c|}{ CSF Total Protein as a Dependent Variable } & \multicolumn{4}{|c|}{ QAlbumin as a Dependent Variable } \\
\hline & $\begin{array}{c}\text { Numerator } \\
\text { df }\end{array}$ & $\begin{array}{c}\text { Denominator } \\
\text { df }\end{array}$ & $\mathbf{F}$ & $p$ Value & $\begin{array}{c}\text { Numerator } \\
\text { df }\end{array}$ & $\begin{array}{c}\text { Denominator } \\
\text { df }\end{array}$ & $\mathbf{F}$ & $p$ Value \\
\hline Sex & 1 & 82 & 0.444 & 0.507 & 1 & 83 & 0.456 & 0.501 \\
\hline Age & 1 & 82 & 0.444 & 0.834 & 1 & 83 & 7.214 & 0.009 \\
\hline Time point & 7 & 82 & 1.83 & 0.092 & 7 & 83 & 1.421 & 0.208 \\
\hline LP method & 1 & 82 & 0.569 & 0.453 & 1 & 83 & 5.461 & 0.022 \\
\hline Time point and sex & 7 & 82 & 0.256 & 0.969 & 7 & 83 & 0.332 & 0.937 \\
\hline Time point and age & 7 & 82 & 1.634 & 0.137 & 7 & 83 & 1.367 & 0.23 \\
\hline $\begin{array}{l}\text { Time point and LP } \\
\text { method }\end{array}$ & 7 & 82 & 0.228 & 0.977 & 7 & 83 & 0.566 & 0.782 \\
\hline LP method and age & 1 & 82 & 0.00 & 0.995 & 1 & 83 & 7.308 & 0.008 \\
\hline $\begin{array}{l}\text { Time point and sex } \\
\text { and age }\end{array}$ & 7 & 82 & 0.105 & 0.998 & 7 & 83 & 0.334 & 0.936 \\
\hline $\begin{array}{l}\text { Time point and sex } \\
\text { and LP method }\end{array}$ & 7 & 82 & 1.093 & 0.375 & 7 & 83 & 0.974 & 0.456 \\
\hline $\begin{array}{l}\text { Time Point and age } \\
\text { and LP method }\end{array}$ & 6 & 82 & 0.25 & 0.958 & 6 & 83 & 0.747 & 0.613 \\
\hline
\end{tabular}

\section{Discussion}

The aims of this study were (1) to confirm recently published changes in CSF routine parameters in a representative cohort of adult nusinersen-treated SMA patients, (2) to assess a potential procedure-based effect caused by repeated LPs on CSF routine parameter changes under nusinersen treatment, and (3) to determine whether nusinersen is well tolerated according to CSF routine parameters in SMA patients with borderline-pathogenic CSF metrics at baseline. Overviewing a treatment period of a maximum of 18 months, we observed a significant elevation in CSF total protein levels and respective QAlbumin values in $38.9 \%$ of cases during the first 10 months of treatment, mainly without significant changes in lactate levels, leukocyte count, and OCB status, which is consistent with previously published data [11]. Elevated total protein levels and QAlbumin values indicate dysfunction of the CSF-blood barrier, which is found in numerous neurological diseases [21-25] or even without any apparent neurological disease [26]. In SMA patients, however, data on CSF total protein and QAlbumin values are sparse. In the past, CSF analysis was rarely performed in SMA patients since the diagnosis is confirmed by genetic testing. Wurster and colleagues reported elevated CSF total protein levels in $20 \%$ of their SMA cohort [11]. In our cohort, $28 \%$ of SMA patients had elevated total protein levels above the general reference interval of $500 \mathrm{mg} / \mathrm{L}$ at baseline. According to a recent study on age-related reference levels of total CSF protein, suggesting an upper reference level of $500 \mathrm{mg} / \mathrm{L}$ for 18-30 years of age and $600 \mathrm{mg} / \mathrm{L}$ for those at age 30 and above, most values seen in our cohort would still be within the normal range [27]. Only four patients $(14.3 \%)$ had CSF protein levels above the age-adjusted upper reference level of $600 \mathrm{mg} / \mathrm{L}$ 
during treatment. While most SMA patients in our cohort had normal total CSF protein levels based on age-adjusted reference intervals, age-adjusted QAlbumin values indicated CSF-blood barrier dysfunction in $25 \%$ of SMA patients at baseline. In amyotrophic lateral sclerosis (ALS), another motor neuron disease, an elevation of CSF QAlbumin values was found in up to $20 \%$ of patients, which was seen as non-specific [28]. Thus, the origin of elevated QAlbumin values in treatment-naive SMA patients remains to be further elucidated and might be related to the neurodegenerative process. A comparative study between different motor neuron diseases, such as ALS or SMA, and healthy controls should be performed to further evaluate this phenomenon. A significant increase in the CSF protein levels and QAlbumin values during regular intrathecally administrated nusinersen might result either from nusinersen itself or its administration via repeated LP.

No clinical parameters influencing CSF protein parameters in SMA patients during the treatment course were identified in a previous study [11]. Consistently, we did not detect any correlation between motor function outcome measures (HFMSE, RULM, 6MWT) and CSF protein parameters both at baseline and during further treatment. However, significant associations between CSF total protein levels and/or QAlbumin values and SMA type, SMN2 copy number, sex, and LP method were identified. An explanation is that CSF total protein levels and QAlbumin levels are age dependent and increase over time $[27,29]$. SMA type 3 and 4 patients in our cohort were older than SMA type 2 patients (median 33.5 vs. 43 years). Since SMA type 3 patients have typically more SMN2 copies [4], patients with a higher SMN2 copy number consequently displayed higher total protein levels and QAlbumin values. Patients who underwent conventional LP (higher number of SMA 3 patients) were older than patients who underwent CT-guided LP (mainly SMA type 2 patients; 34 vs. 46 years). Therefore, we suppose that the patients' age mainly explains different findings for total protein levels and QAlbumin values, as previously described by Wurster et al. [11]. Multivariate analysis revealed that both age and the LP method influenced total protein levels and QAlbumin values in an additive manner. Therefore, in addition to age, which is well known to have an impact on CSF protein levels, the LP method also contributes to increases in total CSF protein levels and QAlbumin values. Higher total protein levels and QAlbumin values in men compared to women have been previously described [29], which is consistent with our findings. It is not known how far CSF changes during repeated LPs are influenced by gender. Our multivariate analysis showed no significant influence of gender on the course of total protein levels and QAlbumin values. QAlbumin values in our study were age-, but not sex adjusted. Castellazzi and colleagues found significant differences in QAlbumin values by a margin of 2.2 units for men [30]. Since revised sex-adjusted reference intervals for total protein levels and QAlbumin values have not been established, we are not able to completely rule out a sex-specific effect on changes in CSF protein parameters after repeated LPs. The interval between each LP might be a relevant factor since significant changes in protein elevation were detected only at the beginning of nusinersen treatment (until month 10), when therapy intervals were shorter compared to the maintenance period (14 to 35 days vs. 4 months). This finding remains after adjusting for SMA patients with CSF-blood barrier dysfunction at baseline, which is consistent with the previously reported elevation of CSF total protein levels found in nusinersen-treated SMA patients with normal CSF routine parameters at baseline [31]. Therefore, we suggest that a short interval between repeated LPs is more likely to result in an elevation of CSF protein parameters, especially against the background of numerous repeated LPs. An adult SMA patient cohort undergoing repeated LP at the same time points and without administration of any drug would have served best to address these questions, but this approach would not be ethically justified any longer. CSF lactate values differed significantly between $\mathrm{d} 0$ and $\mathrm{m} 6, \mathrm{~m} 10$, and $\mathrm{m} 18$ but stayed stable within the normal range throughout nusinersen therapy. Lactate values in the CSF serve to differentiate bacterial from viral meningitis [32], but no patient in our cohort demonstrated either further suspect CSF findings or clinical features of meningitis. Therefore, we consider these changes as non-specific. 
Our results contain important information for the new field of gene-specific therapies. Ongoing studies on ASO treatment for genetic variants of ALS [33-35] will further elucidate how repeated LPs potentially change CSF protein parameters.

At baseline, in $28.6 \%$ of SMA patients, at least one abnormal CSF parameter was detected (7.1\% with positive OCB, $25 \%$ with CSF-blood barrier dysfunction). In a previously published study, positive OCB were found in 3.9\% and CSF-blood barrier disorder in $24.6 \%$ of nusinersen-treated SMA patients at baseline [11]. In our study, SMA patients with CSF-blood barrier dysfunction at baseline did not report side effects more frequently than SMA patients with normal QAlbumin values. The OCB status was not related to side effects, either. However, two SMA patients of our cohort developed CSF-specific OCB under treatment with nusinersen, though this finding was temporary. No data are available regarding incidental findings of positive OCB in SMA. Considering other motor neuron diseases, positive OCB were detected in $3.5 \%$ of patients with ALS [36]. Therefore, positive OCB rather seem to be incidentally present in different motor neuron diseases such as SMA, since both patients with positive OCB findings at baseline in our study displayed no signs of infectious or autoimmune CNS disease. The transient appearance of CSF-specific OCB observed in two SMA patients in our study may be attributable to nusinersen treatment, though further investigation is necessary to determine a possible CSF immune reaction against nusinersen. Altogether, SMA patients with abnormal CSF routine parameters did not report side effects more frequently. None of our patients reported any symptoms of increased intracranial pressure indicating hydrocephalus. However, we did not perform further cranial imaging to rule out asymptomatic hydrocephalus. Further diagnostics of hydrocephalus, i.e., cranial imaging or measuring CSF opening pressure, could give further information regarding the possible development of asymptomatic hydrocephalus in patients undergoing repeated LP, especially in nusinersen-treated SMA patients [37].

\section{Conclusions}

This study confirms the previous findings on mild changes in CSF routine parameters in adult SMA patients under nusinersen treatment. Our results confirm the notion that intrathecal administration of nusinersen in adult SMA patients is generally safe and well tolerated. Conspicuous pre-treatment CSF findings such as OCB had no impact on the tolerability of nusinersen. Considering ongoing studies assessing intrathecal administration of ASOs in other neurological diseases, it is important to further investigate and monitor CSF routine parameters.

Supplementary Materials: The following are available online at https:/ /www.mdpi.com/2076-342 5/11/3/296/s1: Table S1: Overview of CSF routine parameters during therapy (d0 to m22); Table S2: Overview of CSF routine parameters during therapy (d0 to m22).

Author Contributions: Conceptualization, L.H.M., A.O., T.S., and S.P.; data curation, A.O.; formal analysis, L.H.M. and A.O.; investigation, C.B., K.F.J., G.R., P.B., O.A.-F., F.W., N.M., M.W.H., S.G., and F.G.; project administration, M.S., T.S., O.S.-K., and S.P.; resources, M.S. and S.P.; supervision, A.O., T.S., O.S.-K., and S.P.; visualization, L.H.M.; writing—original draft, L.H.M., A.O., O.S.-K., and S.P.; writing-review and editing, L.H.M., A.O., C.B., K.F.J., G.R., P.B., O.A.-F., F.W., N.M., M.W.H., S.G., F.G., M.S., T.S., O.S.-K., and S.P. All authors have read and agreed to the published version of the manuscript.

Funding: This research received no external funding. A.O. is supported by PRACTIS-Clinician Scientist Program of Hannover Medical School, funded by the German Research Foundation (DFG, ME 3696/3-1, 2019-2022). O.S-K. is funded by the German Neuromuscular Society Deutsche Gesellschaft fuer Muskelkranke (DGM e.V.), 2019-2021, grant number Sc 23/1, and the Ellen-Schmidt-ProgramHabilitationsfoerderung fuer Wissenschaftlerinnen, Hannover Medical School (2021).

Institutional Review Board Statement: The trial was conducted in accordance with the Declaration of Helsinki (as revised in 2013). The study was approved by the local ethics committee of the Hannover Medical School (approval number 2413-2014). 
Informed Consent Statement: Informed consent was obtained from all subjects involved in the study.

Data Availability Statement: All data generated or analyzed during this study are included in this published article.

Acknowledgments: The authors thank Karin Fricke, Kathrin Scheiwe, Sabine Lang, Katharina Dorsch, Georgia Mysegades, Beate Klose, Ilona Cierpka-Leja, and Mathias Rhein for excellent technical assistance. Finally, the authors wish to thank all patients for participating in this study.

Conflicts of Interest: All authors have completed the ICMJE uniform disclosure form. L.H.M. reports personal fees from Biohaven Pharmaceuticals, outside the submitted work. G.R. reports personal fees from Biogen $\mathrm{GmbH}$, during the conduct of the study. A.O. reports personal fees from Biogen $\mathrm{GmbH}$; grants from PRACTIS-Clinician Scientist Program of Hannover Medical School, funded by the German Research Foundation (DFG, ME 3696/3-1, 2020-2022), during the conduct of the study; and personal fees from Impulze $\mathrm{GmbH}$, outside the submitted work. O.S.-K. reports personal fees from Biogen $\mathrm{GmbH}$; grants from Young Faculty Program, Hannover Medical School, during the conduct of the study; grants and personal fees from German Neuromuscular Society (Deutsche Gesellschaft fuer Muskelkranke e.V.); and personal fees from Biermann Verlag $\mathrm{GmbH}$, outside the submitted work. T.S. reports personal fees from Alexion, Alnylam, Bayer Vital, Biogen, Celgene, CSL Behring, Merck, Novartis, Roche, and Sanofi Aventis, outside the submitted work; T.S. is serving as an unpaid editorial board member of Annals of Translational Medicine from Jan 2020 to Dec 2021. M.S. reports personal fees from Bayer Healthcare, personal fees from Takeda, personal fees from CSL Behring, grants and personal fees from Sanofi-Genzyme, personal fees from Grifols, grants and personal fees from Merck-Serono, personal fees from Roche, grants and personal fees from Novartis, personal fees from Teva, personal fees from Alexion, grants and personal fees from Biogen, and personal fees from Janssen, outside the submitted work. S.P. reports grants from the German Neuromuscular Society, grants from the Federal Ministry of Education and Research (BMBF), personal fees from Cytokinetics, Inc., personal fees from Desitin Pharma, personal fees from Biogen, personal fees from Novartis, personal fees from TEVA, grants from German Israeli Foundation (GIF) for Scientific Research and Development, grants from the EU Joint Programme for Neurodegenerative Disease Research (JPND), and personal fees from Roche, outside the submitted work. S.G. reports personal fees from Merck and Alnylam, outside the submitted work. C.B., F.W., N.M., M.W.H., S.G., F.G., O.A.-F., and P.B. have nothing to disclose.

\section{References}

1. Rus, A.A. FDA Approval of Nusinersen for Spinal Muscular Atrophy Makes 2016 the Year of Splice Modulating Oligonucleotides. Nucleic Acid Ther. 2017, 27, 67-69.

2. Kolb, S.J.; Kissel, J.T. Spinal Muscular Atrophy. Neurol. Clin. 2015, 33, 831-846. [CrossRef]

3. Prior, T.; Leach, M.; Finanger, E. Spinal Muscular Atrophy. In GeneReviews ${ }^{\circledR} ;$ Adam, M.P., Ardinger, H.H., Pagon, R.A., Eds.; University of Washington: Seattle, WA, USA, 1993-2020. Available online: https://www.ncbi.nlm.nih.gov/books/NBK1352/ (accessed on 14 November 2019).

4. Butchbach, M.E.R. Copy Number Variations in the Survival Motor Neuron Genes: Implications for Spinal Muscular Atrophy and Other Neurodegenerative Diseases. Front. Mol. Biosci. 2016, 3, 7. [CrossRef]

5. Bennett, C.F.; Baker, B.F.; Pham, N.; Swayze, E.; Geary, R.S. Pharmacology of Antisense Drugs. Annu. Rev. Pharmacol. Toxicol. 2017, 57, 81-105. [CrossRef] [PubMed]

6. Singh, N.N.; Lee, B.M.; DiDonato, C.J.; Singh, R.N. Mechanistic principles of antisense targets for the treatment of spinal muscular atrophy. Futur. Med. Chem. 2015, 7, 1793-1808. [CrossRef]

7. Chiriboga, C.A.; Swoboda, K.J.; Darras, B.T.; Iannaccone, S.T.; Montes, J.; De Vivo, D.C.; Norris, D.A.; Bennett, C.F.; Bishop, K.M. Results from a phase 1 study of nusinersen (ISIS-SMN(Rx)) in children with spinal muscular atrophy. Neurology 2016, 86, 890-897. [CrossRef] [PubMed]

8. Mercuri, E.; Darras, B.T.; Chiriboga, C.A.; Day, J.W.; Campbell, C.; Connolly, A.M.; Iannaccone, S.T.; Kirschner, J.; Kuntz, N.L.; Saito, K.; et al. Nusinersen versus Sham Control in Later-Onset Spinal Muscular Atrophy. N. Engl. J. Med. 2018, 378, 625-635. [CrossRef] [PubMed]

9. Finkel, R.S.; A Chiriboga, C.; Vajsar, J.; Day, J.W.; Montes, J.; De Vivo, D.C.; Yamashita, M.; Rigo, F.; Hung, G.; Schneider, E.; et al. Treatment of infantile-onset spinal muscular atrophy with nusinersen: A phase 2, open-label, dose-escalation study. Lancet 2016, 388, 3017-3026. [CrossRef]

10. Wurster, C.D.; Günther, R.; Steinacker, P.; Dreyhaupt, J.; Wollinsky, K.; Uzelac, Z.; Witzel, S.; Kocak, T.; Winter, B.; Koch, J.C.; et al. Neurochemical markers in CSF of adolescent and adult SMA patients undergoing nusinersen treatment. Ther. Adv. Neurol. Disord. 2019, 12. [CrossRef] 
11. Wurster, C.D.; Koch, J.C.; Cordts, I.; Dreyhaupt, J.; Otto, M.; Uzelac, Z.; Witzel, S.; Winter, B.; Kocak, T.; Schocke, M.; et al. Routine Cerebrospinal Fluid (CSF) Parameters in Patients with Spinal Muscular Atrophy (SMA) Treated with Nusinersen. Front. Neurol. 2019, 10. [CrossRef]

12. Gingele, S.; Hümmert, M.W.; Alvermann, S.; Jendretzky, K.F.; Bönig, L.; Brieskorn, M.; Schwenkenbecher, P.; Sühs, K.-W.; Müschen, L.H.; Osmanovic, A.; et al. Routine Cerebrospinal Fluid Cytology Reveals Unique Inclusions in Macrophages during treatment with Nusinersen. Front. Neurol. 2019, 10, 735. [CrossRef]

13. von Elm, E.; Altman, D.G.; Egger, M.; Pocock, S.J.; Gotzsche, P.C.; Vandenbroucke, J.P.; Initiative, S. The Strengthening the Reporting of Observational Studies in Epidemiology (STROBE) statement: Guidelines for reporting observational studies. Prev. Med. 2007, 45, 247-251. [CrossRef] [PubMed]

14. Stolte, B.; Totzeck, A.; Kizina, K.; Bolz, S.; Pietruck, L.; Mönninghoff, C.; Guberina, N.; Oldenburg, D.; Forsting, M.; Kleinschnitz, C.; et al. Feasibility and safety of intrathecal treatment with nusinersen in adult patients with spinal muscular atrophy. Ther. Adv. Neurol. Disord. 2018, 11. [CrossRef] [PubMed]

15. Mazzone, E.S.; Mayhew, A.; Montes, J.; Ramsey, D.; Fanelli, L.; Young, S.D.; Salazar, R.; De Sanctis, R.; Pasternak, A.; Glanzman, A.; et al. Revised upper limb module for spinal muscular atrophy: Development of a new module. Muscle Nerve 2017, 55, 869-874. [CrossRef]

16. Main, M.; Kairon, H.; Mercuri, E.; Muntoni, F. The Hammersmith Functional Motor Scale for Children with Spinal Muscular Atrophy: A Scale to Test Ability and Monitor Progress in Children with Limited Ambulation. Eur. J. Paediatr. Neurol. 2003, 7 , 155-159. [CrossRef]

17. Young, D.S.; Montes, J.; Kramer, S.S.; Marra, J.; Salazar, R.; Cruz, R.; Chiriboga, C.A.; Garber, C.E.; De Vivo, D.C. Six-minute walk test is reliable and valid in spinal muscular atrophy. Muscle Nerve 2016, 54, 836-842. [CrossRef]

18. Schwenkenbecher, P.; Janssen, T.; Wurster, U.; Konen, F.F.; Neyazi, A.; Ahlbrecht, J.; Puppe, W.; Bönig, L.; Sühs, K.W.; Stangel, M.; et al. The Influence of Blood Contamination on Cerebrospinal Fluid Diagnostics. Front. Neurol. 2019, 10, 584. [CrossRef] [PubMed]

19. Reiber, H. Cerebrospinal fluid-physiology, analysis and interpretation of protein patterns for diagnosis of neurological diseases. Mult. Scler. 1998, 4, 99-107. [PubMed]

20. Wurster, U. Demonstration of oligoclonal IgG in the unconcentrated CSF by silver stain. In Electrophoresis Berlin; Stathakos, D., Ed.; Walter de Gruyter and Co.: Berlin, Germany, 1983; Volume 1982, pp. 250-259.

21. Ahlbrecht, J.; Hillebrand, L.K.; Schwenkenbecher, P.; Ganzenmueller, T.; Heim, A.; Wurster, U.; Stangel, M.; Sühs, K.-W.; Skripuletz, T. Cerebrospinal fluid features in adults with enteroviral nervous system infection. Int. J. Infect. Dis. 2018, 68, 94-101. [CrossRef] [PubMed]

22. Skripuletz, T.; Pars, K.; Schulte, A.; Schwenkenbecher, P.; Yildiz, Ö.; Ganzenmueller, T.; Kuhn, M.; Spreer, A.; Wurster, U.; Pul, R.; et al. Varicella zoster virus infections in neurological patients: A clinical study. BMC Infect. Dis. 2018, 18, 238. [CrossRef] [PubMed]

23. Skripuletz, T.; Schwenkenbecher, P.; Pars, K.; Stoll, M.; Conzen, J.; Bolat, S.; Pul, R.; Vonberg, R.-P.; Sedlacek, L.; Wurster, U.; et al. Importance of Follow-Up Cerebrospinal Fluid Analysis in Cryptococcal Meningoencephalitis. Dis. Markers 2014, 2014, 1-10. [CrossRef] [PubMed]

24. Nagy, K.; Skagervik, I.; Tumani, H.; Petzold, A.; Wick, M.; Kühn, H.-J.; Uhr, M.; Regeniter, A.; Brettschneider, J.; Otto, M.; et al. Cerebrospinal fluid analyses for the diagnosis of subarachnoid haemorrhage and experience from a Swedish study. What method is preferable when diagnosing a subarachnoid haemorrhage? Clin. Chem. Lab. Med. 2013, 51, 2073-2086. [CrossRef]

25. Bönig, L.; Möhn, N.; Ahlbrecht, J.; Wurster, U.; Raab, P.; Puppe, W.; Sühs, K.-W.; Stangel, M.; Skripuletz, T.; Schwenkenbecher, P. Leptomeningeal Metastasis: The Role of Cerebrospinal Fluid Diagnostics. Front. Neurol. 2019, 10, 10. [CrossRef]

26. Brettschneider, J.; Claus, A.; Kassubek, J.; Tumani, H. Isolated blood-cerebrospinal fluid barrier dysfunction: Prevalence and associated diseases. J. Neurol. 2005, 252, 1067-1073. [CrossRef] [PubMed]

27. Hegen, H.; Auer, M.; Zeileis, A.; Deisenhammer, F. Upper reference limits for cerebrospinal fluid total protein and albumin quotient based on a large cohort of control patients: Implications for increased clinical specificity. Clin. Chem. Lab. Med. 2016, 54, 285-292. [CrossRef]

28. Sussmuth, S.D.; Tumani, H.; Ecker, D.; Ludolph, A.C. Amyotrophic lateral sclerosis: Disease stage related changes of tau protein and S100 beta in cerebrospinal fluid and creatine kinase in serum. Neurosci. Lett. 2003, 353, 57-60. [CrossRef] [PubMed]

29. McCudden, C.R.; Brooks, J.; Figurado, P.; Bourque, P.R. Cerebrospinal Fluid Total Protein Reference Intervals Derived from 20 Years of Patient Data. Clin. Chem. 2017, 63, 1856-1865. [CrossRef]

30. Castellazzi, M.; Morotti, A.; Tamborino, C.; Alessi, F.; Pilotto, S.; Baldi, E.; Caniatti, L.M.; Trentini, A.; Casetta, I.; Granieri, E.; et al. Increased age and male sex are independently associated with higher frequency of blood-cerebrospinal fluid barrier dysfunction using the albumin quotient. Fluids Barriers CNS 2020, 17, 1-9. [CrossRef]

31. Kessler, T.; Latzer, P.; Schmid, D.; Warnken, U.; Saffari, A.; Ziegler, A.; Kollmer, J.; Möhlenbruch, M.; Ulfert, C.; Herweh, C.; et al. Cerebrospinal fluid proteomic profiling in nusinersen-treated patients with spinal muscular atrophy. J. Neurochem. 2020, 153, 650-661. [CrossRef]

32. Huy, N.T.; Thao, N.T.H.; Diep, D.T.N.; Kikuchi, M.; Zamora, J.; Hirayama, K. Cerebrospinal fluid lactate concentration to distinguish bacterial from aseptic meningitis: A systemic review and meta-analysis. Crit. Care 2010, 14, R240. [CrossRef] 
33. Miller, T.; Cudkowicz, M.; Shaw, P.J.; Andersen, P.M.; Atassi, N.; Bucelli, R.C.; Genge, A.; Glass, J.; Ladha, S.; Ludolph, A.L.; et al. Phase 1-2 Trial of Antisense Oligonucleotide Tofersen for SOD1 ALS. N. Engl. J. Med. 2020, 383, 109-119. [CrossRef] [PubMed]

34. Brenner, D.; Freischmidt, A.; Ludolph, A.C.; Weishaupt, J.H. Gene-specific treatment approaches in amyotrophic lateral sclerosis in the present and future. Nervenarzt 2020, 91, 287-293. [CrossRef]

35. Miller, T.; Cudkowicz, M.; Shaw, P.; Benett, F.; Lane, R.; Graham, D.; Nestorov, I.; Fanning, L.; Chang, I.; McNeill, M.; et al. C11 safety, PK, PD, and exploratory efficacy in single and multiple dose study of a SOD1 antisense oligonucleotide (tofersen) in participants with ALS. Platform Communications. Abstract Book-30th International Symposium on ALS/MND (Complete printable file). Amyotroph. Lateral Scler. Front. Degener. 2019, 20, 1-99.

36. Ticozzi, N.; Tiloca, C.; Mencacci, N.E.; Morelli, C.; Doretti, A.; Rusconi, D.; Colombrita, C.; Sangalli, D.; Verde, F.; Finelli, P.; et al. Oligoclonal bands in the cerebrospinal fluid of amyotrophic lateral sclerosis patients with disease-associated mutations. J. Neurol. 2012, 260, 85-92. [CrossRef] [PubMed]

37. Spinraza (nusinersen). Communicating Hydrocephalus Not Related to Meningitis or Bleeding Reported. Available online: https:/ / www.hpra.ie/docs/default-source/default-document-library/important-safety-information (accessed on 23 December 2020). 